
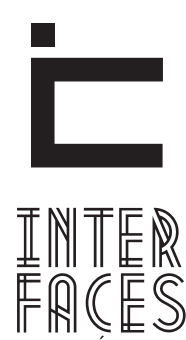

CIENTIIFICAS

HUMANAS E SOCIAIS

ISSN IMPRESSO 2316-3348

E-ISSN 2316-3801

DOI - 10.17564/2316-3801.2017v6n1p113-122

\title{
A ONOMATOPÉIA DO HOMEM-URUBU: OTRABALHO COM COLETA DE MATERIAIS RECICLÁVEIS
}

\author{
THE ONOMATOPOEIA VULTUREMAN: WORKING WITH COLLECT RECYCLABLE MATERIALS \\ LA ONOMATOPEYA DEL HOMBRE-BUITRE: TRABAJO CON RECOLECTA DE MATERIALES DE RECICLAJE
}

Mariana Boulitreau Siqueira Campos Barros ${ }^{1}$

Anselmo Cesar Vasconcelos Bezerra ${ }^{3}$

Sandro Ramos Batista ${ }^{5}$
Naiara Raissa Souza Santos ${ }^{2}$

Débora Morgana Soares Oliveira do $0^{4}$

Magaly Bushatsky

\section{RESUMO}

Este estudo tem por objetivos compreender a rotina de trabalho dos catadores de resíduos recicláveis na comunidade de Beira da Maré em Recife-PE, assim como conhecer suas percepções em relação aos direitos e deveres do trabalhador. Tratou-se de um estudo interpretativo, de natureza qualitativa com catadores de resíduos adscritos em uma Unidade de Saúde da Família (USF) no município de Recife, Pernambuco. Optou-se pela técnica de análise de conteúdo segundo Bardin (1979). O estudo foi analisado por quatro eixos norteadores: TRABALHO EM COLETA DE RESÍDUOS: UMA DETERMINAÇÃO SOCIAL? Estes trabalhadores acumulam um histórico de força de trabalho frágil e vulnerável e possuem algum outro meio de sustento. ARTIFÍCIOS DE SOBREVIVÊNCIA: O PROCESSO DE
TRABALHO DOS CATADORES DE RESÍDUOS: Observou-se uma "disputa" pelo material coletado onde não havia uma movimentação de cooperação, ou intencionalidade de formação de associações ou de mobilidade social. SIGNIFICADOS DO “HOMEM-URUBU”: DIREITOS E DEVERES DO TRABALHADOR: os entrevistados explanam a importância que representam no cenário em que os cercam, contudo, colocam-se sem direitos e desconhecem deveres. LIVRE EXPRESSÃO: observou-se o reconhecimento de um trabalho de risco e da sobrecarregada carga de trabalho. Os profissionais da Beira da Maré reconhecem, mesmo indiretamente, que não gozam de nenhum amparo referente aos direitos sociais. As esfinges nas articulações no processo de trabalho retratam uma relação frágil 
e a necessidades de implantação de políticas com fins de reconhecimento social assim como intervenções que fortaleçam a formação de uma rede de cooperação e de condições laborais seguras.

\section{ABSTRACT}

This study aims to understand the work routine of recyclable waste pickers in the border community of Maré in Recife, as well as to know their perceptions of the worker's rights and duties. This was an interpretative study, a qualitative nature with ascribed waste pickers in a Family Health Unit (USF) in the city of Recife, Pernambuco analyzed by Bardinsecond content analysis technique has identified four guiding principles: WORK IN COLLECTING WASTE: a SOCIAL DETERMINATION ?: These workers accumulate a history of fragile and vulnerable workforce and have some other means of livelihood. DEVICES OF SURVIVAL: THE PROCESS OF WORK OF WASTE COLLECTORS: There was a "dispute" the material collected which there is a cooperative movement, intentionality or training associations or social mobility. MEANING OF “VULTUREMAN": WORKER RIGHTS AND DUTIES:

\section{PALAVRAS-CHAVE}

Catadores. Uso de Resíduos Sólidos. Trabalho. respondents speaking of importance representing the scenario surrounding them, however, are placed without rights and duties unaware. FREE EXPRESSION: it noted the recognition of a risk of labor and overburdened workload. The professionals of border community of Maré in Recife recognize, even indirectly, which do not enjoy any protection regarding social rights. Sphinxes in the joints in the work process depict a fragile relationship and the implementation of policy needs with social recognition purposes as well as interventions that enhance the formation of a network of cooperation and safe working conditions.

\section{KEYWORDS}

Solid Waste Segregators. Solid Waste Use. Work

\section{RESUMEN}

Este estudio tiene como objetivo comprender la rutina de trabajo de los recolectores de residuos reciclables en la comunidad Beira de Maré en Recife, así como para conocer sus percepciones sobre los derechos y deberes del trabajador. Este fue un estudio interpretativo de carácter cualitativo, con los recicladores asignados a la Unidad de Salud de la Familia (USF) en la ciudad de Recife, Pernambuco, analizado por técnica de análisis de contenido de Bardin. Fue identificado cuatro principios rectores: EL TRABAJO EN LA RECOLECTA DE RESIDUOS: ¿UNA DETERMINACIÓN SOCIAL?: Estos trabajadores acumulan una historia de fuerza de trabajo frágil y vulnerable y tienen algunos otros medios de vida. DISPOSITIVOS DE SUPERVIVENCIA: EL PROCESO DE TRABAJO DE LOS RECOLECTORES DE RESIDUOS: Se ha producido una "disputa" por el material recogido donde no había un movimiento cooperativo, o la intencionalidad de formación de asociaciones de movilidad social. SIGNIFICADO DEL "HOMBRE-BUITRE": LOS DERECHOS Y DEBERES LABORALES: LOS encuestados habla de la importancia que representa el escenario que les rodea, sin embargo, se colocan sin derechos y obligaciones inconscientes. LIBRE EXPRESIÓN: 
se observó el reconocimiento de un riesgo de trabajo y la carga de trabajo sobrecargado. Los profesionales de la comunidad Beira de Maré en Recife reconocen, aunque sea indirectamente, que no gozan de ninguna protección en materia de derechos sociales. Las esfinges en las articulaciones en el proceso de trabajo representan una relación frágil y la necesidad de aplicación de políticas con fines de reconocimiento social, así como las intervenciones que mejoran la formación de una red de cooperación y de condiciones de trabajo seguras.

\section{PALABRAS-CLAVES}

Recolectores de Residuos Sólidos. Uso de Residuos Sólidos. Trabajo.

\section{INTRODUÇ̃̃̃O}

A mudança no estilo de vida, em função do desenvolvimento econômico, da industrialização e da globalização, tem causado, por um lado, os benefícios trazidos pela ampliação de recursos energéticos, o avanço da ciência e os benefícios sociais acarretados por este processo. Mas, por outro lado, tem revelado a séria ameaça acarretada sobre a perda da biodiversidade, bem como sobre as condições de saúde, cultura, emprego e sobrevivência de populações diretamente afetadas. (MENDES, 2011; KOIFMAN, 2001)

Assim, instalada, em um contexto provocado pela forma de consumo instituída e pela geração de resíduos sólidos urbanos, surgem os catadores de materiais recicláveis, como um fenômeno na escala da exclusão social (SIQUEIRA; MORAIS, 2009).

Para MIURA (2004) o problema hoje não está em reconhecer legalmente o catador como um profissional, mas sim, em reconhecer seu direito às condições dignas de trabalho e de vida para além da perspectiva estrita da sobrevivência.

Essa atividade, que tem atraído número crescente de excluídos do mercado formal de trabalho, reflete uma percepção negativa da sociedade sobre os catadores, a qual interagem com a autoimagem que eles formam de si próprios, apresentando-se, assim, esfinges nos princípios da cidadania e no enquadramento de detentores de direitos e deveres (DALL'AGNOL et al., 2007; VELLOSO, 2005).

0 aumento do consumo e a consequente produção de resíduos relacionam-se com o surgimento de um trabalho informal em que o cotidiano dos coletores de resíduos está envolvido em um processo de trabalho árduo e de risco. Faz-se, então, necessária a concepção de suas práticas e subjetividades a partir de acúmenes em relação aos seus direitos e deveres.

Este estudo tem como objetivos compreender a rotina de trabalho dos catadores de resíduos recicláveis na comunidade de Beira da Maré em Recife-PE, assim como conhecer suas percepções em relação aos direitos e deveres do trabalhador.

\section{MÉTODO}

Tratou-se de um estudo interpretativo, de natureza qualitativa, caracterizado pela observação direta dos coletores de resíduos. A amostra foi selecionada por conveniência e realizada em outubro e novembro de 2012. composta por catadores de resíduos adscritos em uma microárea de abrangência da Unidade de Saúde da Família (USF) de Cafesópolis na comunidade Beira da Maré localizado no bairro da Imbiribeira no município de Recife, Pernambuco, totalizando seis catadores autônomos, sendo dois do sexo masculino e quatro analfabetos.

$O$ instrumento de coleta de dados foi utilizado um roteiro de entrevista semiestruturado produzida pelos pesquisadores. As informações foram gravadas, posteriormente transcritas e analisadas pela técnica de análise de conteúdo, segundo BARDIN (1979). 
O estudo foi analisado por quatro eixos norteadores ou principais de análise, conforme os discursos dos entrevistados: Trabalho em coleta de resíduos: uma determinação social?, Artifícios de sobrevivência: o processo de trabalho dos catadores de resíduos, Significados do "homem-urubu": direitos e deveres do trabalhador e Livre expressão.

Foram obedecidos neste estudo os preceitos da bioética registrados na Resolução 466/12 do Consetho Nacional de Ética em Pesquisa (CONEP) e suas complementares do Ministério da Saúde, sobre pesquisa, envolvendo seres humanos.

0 projeto foi cadastrado na Plataforma Brasil e aprovado pelo Comitê de Ética em Pesquisa do Instituto de Medicina Integral Professor Fernando Figueira (IMIP) sob CAAE: 06506312.3.0000.5201. Adotou-se como critérios de inclusão estar cadastrado na área de abrangência da Unidade de Saúde da Família Cafesópolis, no bairro da Imbiribeira, Recife-PE, trabalhar com coleta e separação de resíduos e ter mais de 18 anos.

Para garantir o anonimato, a ética, e o sigilo das informações coletadas, os nomes foram fictícios, substituídos por personalidades Pernambucanas. Os nomes das mulheres assumiram um episódio pouco conhecido da história brasileira: o primeiro conito armado registrado no país com participação de mulheres, batizado de Batalha de Tejucupapo. 0 confronto se deu entre 1630 e 1654 durante a ocupação do Nordeste, particularmente Pernambuco, por parte dos holandeses (ALVES FIHO, 2011).

Os nomes dos homens foram mencionados em homenagem a Nelson Rodrigues e Josué de Castro. 0 primeiro é possuidor de uma extensa produção literária que colaborou para o roteiro de inúmeras adaptações cinematográficas (ANDRADE, 2007). O segundo, um conceituado fisiólogo, geógrafo, pesquisador e historiador, famoso por sua obra Geografia da Fome (CASTRO, 1984).

\section{RESULTADOSE DISCUSSÃO}

0 artigo $1^{\circ}$ da Constituição da República Federativa do Brasil de 1988 estatui como fundamentos da república, entre outros, a cidadania, a dignidade da pessoa humana e os valores sociais do trabalho e da livre iniciativa, bem como, conforme o artigo $5^{\circ}$, caput, que todos são iguais perante a lei, sem distinção de qualquer natureza (BRASIL, 1988)

Na identificação deste tripé: cidadania-dignidade-trabalho, a Classificação Brasileira de Ocupações (CBO), classifica o trabalho de catador de resíduos como aquele exercido a céu aberto e em horários variados por profissionais que se organizam de forma autônoma ou em cooperativas (MTE, 2002)

Como o urubu que se alimenta de frutos podres e carnes de animais mortos em decomposição e, por esse estranho hábito alimentar, tem um importante papel sanitário, porque retiram o material orgânico em decomposição da superfície do solo, o catador de resíduos recicláveis, aqui denominado homem-urubu, usufrui dos "restos" da modernidade para o seu sustento e atua em um trabalho insalubre, diminuindo o impacto ambiental das atividades humanas (FIOCRUZ, 2013)

Em 2013, o Brasil, conforme o Instituto de Pesquisa Econômica Aplicada (IPEA), estimou que o país tivesse entre 400 e 600 mil profissionais da catação de recicláveis, sendo que, desses, apenas $10 \%$ estariam organizados (IPEA, 2015)

Os dados deste estudo, entretanto, foram apreciados a partir de seis catadores autônomos, sendo dois do sexo masculino e quatro analfabetos, durante atividades assistenciais da Residência Multiprofissional em Saúde, com foco em saúde da família.

\subsection{TRABALHO EM COLETA DE RESÍDUOS: UMA DETERMINAÇÃO SOCIAL?}

0 que determinou estes trabalhadores a tirarem dos resíduos seus sustentos e uma alternativa para a sobrevivência? Para enfatizar o conhecimento de questões trabalhistas e levantar estes possíveis determinantes buscou-se questionar quais os antecedentes laborais: "já lavei roupa." (Maria Clara) "Trabalhava em casa de família..." (Maria Quitéria). “Já trabalhei na agricultura limpando mato, cana..." (Nelson Rodrigues). 
E se já teve a carteira assinada: "eu tinha carteira assinada de serviços gerais, mas agora a idade, a leitura, essas coisas, já fica meio difícil de você arranjar um serviço" (Joaquina)

Como herdeiros da desigualdade oriunda do sistema econômico capitalista, estes trabalhadores acumulam um histórico de força de trabalho frágil e vulnerável os quais, ao optarem por uma atividade que não exige filiação ou vínculo, encontram a coleta de resíduos uma saída pela falta de oportunidade em outras atividades ou pelo não acesso à educação e capacitação: "trabalhei numa fábrica e fiquei sete meses e quando a dona descobriu que eu não sabia assinar meu nome, me colocou para fora!" (Maria Camarão).

Buscou-se compreender a razão e o princípio desta alternativa de trabalho que, por intermédio de catadores próximos e pela falta de emprego, labutam na exclusão da exclusão (SOUSA, 2007; CARMO, 2009):

Foi por necessidade, que eu não tinha emprego e meu marido também não. (Maria Clara).

Meu marido ficou desempregado, correu muito atrás de um emprego mas não conseguiu, aí ele (o vizinho) arrumou uma carroça. (Maria Camarão).

De fato, o chamado "mercado de trabalho" vem sendo radicalmente reestruturado e todas as "inovações” levam à precarização das condições de vida da massa dos vendedores de força de trabalho: a ordem do capital é hoje, reconhecidamente, a ordem do desemprego e da "informalidade". (NETTO, 2012)

\subsection{ARTIFÍCIOS DE SOBREVIVÊNCIA: O PROCESSO DE TRABALHO DOS CATADORES DE RESÍDUOS.}

0 acesso ao trabalho de catador é livre, sem exigência de escolaridade ou formação profissional. Coletar material reciclável e reaproveitável, separar e preparar o material para expedição, realizar manutenção do ambiente e equipamentos, divulgar o trabalho de reciclagem são algumas das atividades descritas pela CBO (2002).

Durante a convivência com os catadores, observou-se que o processo de catação ocorre nas ruas próximas da comunidade, com carroças, muitas vezes improvisadas com ferragens provenientes de ferro-vetho, a separação realizada e armazenada nos arredores e até mesmo na casa dos próprios catadores. No entanto, compreendeu-se, também, que não há uma movimentação de cooperação, ou intencionalidade de formação de associações ou de mobilidade social, movimentos em prol de uma organização de trabalho.

Este processo culminou em uma atividade empreendedora, o qual se observa, diretamente e nos discursos, que um carroceiro e sua esposa que é separadora, "contratam" mulheres para participar da seleção dos resíduos, à medida que as mesmas não possuem 0 meio de coletar os materiais recicláveis, estabelecendo, dessa forma, uma relação empregado-empregador:

\begin{abstract}
Quando aparece alguma coisa a mais (referente a mais material reciclável) ele (empregador) dá um trocadinho... (Joaquina).

Eu trabalho com seu Fulano... eu vendo pra ele mesmo... o que ele fizer por mim tá bom, eu dou pra ele e ele vende para o 'atravessador', eu só sou trabalhador... (Nelson Rodrigues).
\end{abstract}

Baseada na Carta Del Lavoro, o Decreto-Lei $n^{\circ}$ 5.452 , de $1^{\circ}$ de maio de 1943 , decreta a aprovação da Consolidação das Leis do Trabalho (CLT), que no Artigo $2^{\circ}$ considera empregador a empresa, individual ou coletiva que, assumindo os riscos da atividade econômica, admite, assalaria e dirige a prestação pessoal de serviço e, no $\S 3^{\circ}$ do mesmo artigo, como empregado, toda pessoa física que prestar serviços de natureza não eventual a empregador, sob a dependência deste e mediante salário. Vê-se que estes conceitos são usurpados por uma relação informal de "contrato", os quais o empregador e o empregado não estabelecem vínculos e não gozam dos direitos e deveres trabalhistas (BRASIL, 1943)

Ademais, o $\S 1^{\circ}$ do artigo $2^{\circ}$ da CLT, equipara a trabalhador, para efeitos de relação empregatícia, o profissional liberal. 0 que, em última análise, enquadra-se, o catador de materiais recicláveis (BRASIL, 1943)

No aprofundamento do processo de trabalho dos catadores, questionou-se o dia a dia desses trabalhadores: o material coletado, o processo de separação, 
armazenagem, local onde são recolhidos e sobre a venda dos mesmos: "Papelão, papel branco, garrafa pet, prástico, latinha de alumínio. Tudo a gente separa, não é nada junto. Eles (atravessador) levam molhado o papelão, mas desconta (Maria Clara).

Para melhor compreensão da rotina de trabalho desses catadores perguntou-se o tempo de trabalho com os resíduos; poucos, entretanto, estão iniciando, com apenas dois meses na coleta. A maioria já está neste dia a dia há um período mais longo, configurando, assim, a não eventualidade, conforme os depoimentos, há mais de cinco anos.

Em relação à carga horária, o cotidiano robusto destes catadores revela um processo árduo de trabatho o qual os intervalos são preenchidos para a realização de necessidades humanas básicas, como comer e dormir: "Tem dia da gente pegar de seis da manhã... a gente descarrega de novo e cata, quando termina faz a pausa para almoçar, aí quando é de tarde ele vem aí a gente vai catar de novo. É o dia todinho assim" (Maria Clara).

Questionou-se se, em caso de adoecimento ou algo que impeça a execução do trabalho, o mesmo contaria com algum seguro social e como obteria seu sustento; em tom de conformismo, todos os trabalhadores concluem que no final do mês o dinheiro vem menos.

Notou-se a percepção de desvantagem e insatisfação dos catadores ao vender o material reciclado para os que eles denominam de "atravessadores"; esses, em contato direto com as fábricas, lucram mais dos resíduos separados por esses trabalhadores, assim como controlam os preços de compra desses materiais "encarcerando" estes catadores na busca da livre escolha para a venda dos produtos de trabalho, configurando, desta forma, a direção da prestação de serviço, elementos da formação da relação empregatícia:

Isso é bom pra quem vende direto pra fábrica, pra quem vende pra atravessador... a gente é que mais trabalha e é quem menos ganha se o dono do depósito for dormir agora e sonhar que o papelão vai abaixar, ele abaixa e a gente não tem a quem recorrer não... (Josué de Castro).
Em uma análise mais rígida, há de se considerar que existe uma relação de emprego entre catador e "atravessador", haja vista possuir um vínculo empregatício em que este mercado é de exclusividade daquele "atravessador" que produz lucro em cima do trabalho do catador de materiais recicláveis. Observa-se, mais uma vez, a relação de subordinação e dependência, reforçando a caracterização de vínculo empregatício.

Em contrapartida, alternativas foram encontradas pelos catadores de resíduos em meio a obstáculos impostos pelas mudanças na coleta realizada pelo órgão público responsável; dessa forma percebe-se a importância de um vínculo de confiança entre catador e produtor de resíduos, para um processo de trabalho mais seguro e resolutivo:

O conhecimento que eu tenho é em um edifício, eu chego lá na portaria, pego a chave, abro a lixeira, eu separo o que serve pra mim e o que não presta amarro na bolsa... o povo pergunta se você não tem um telefone, você dá o número e o que aparece, ele liga e eu vou buscar... (Josué de Castro).

Além da renda com o trabalho da coleta, todos possuem algum outro meio de sustento. Os mesmos realizam trabalhos informais ou autônomos, ou estão cadastrados em programas sociais do Governo Federal, para complementação da renda como mostram os relatos abaixo: "Os picolé de bolsinha que eu vendo pra ajudar”(Maria Camarão). “tenho duas lavagens de roupa” (Joaquina). "A renda que tenho só é bolsa família e bolsa escola” (Maria Quitéria).

Comparando-se com estudos realizados em cooperativas, em que a relação dos catadores com 0 trabalho oscila entre a ideia de tarefa temporária, enquanto não aparece uma oportunidade com carteira assinada e a de uma atividade interessante por possibilitar rendimentos maiores do que num emprego formal, os trabalhadores de Beira da Maré veem a coleta como uma atividade laboral alternativa e sem estímulos para buscar um emprego formal mesmo alguns referindo rendimentos inferiores (CARMO, 2009)

Observa-se, contudo, uma diferença na satisfação da renda entre aqueles que trabalham na coleta e "em- 
pregam" informalmente outras pessoas, ou seja, os que assumem papel de empreendedor e terceirizam o trabalho de outros catadores, e os que são "empregados" e os autônomos, ou seja, uma representação do modo de produção vigente o qual prioriza o lucro e a exploração da força de trabalho humano, mesmo que esta aconteça em meio aos vulneráveis sobre os mais vulneráveis:

Empregador: eu faço minha feira, ajudo minha filha, pago aos meninos que me ajudam. (Maria Clara); Empregado: Não dá. (Joaquina);

Autônomo: não dá não viu... só dá pra comprar o grosso: arroz, feijão, macarrão... só comida... (Maria Camarão).

\subsection{SIGNIFICADOS DO “HOMEM-URUBU”: DIREITOS E DEVE- RES DO TRABALHADOR}

Ao adotar o conceito de Hans Kelsen sobre o Direito, que em uma postura positiva formula: "[...] o Direito [...] é uma ordem normativa da conduta humana, ou seja, um sistema de normas que regulam o comportamento humano" (KELSEN apud PADILHA JÚNIOR, 2007, p. 74)

Após uma descrição e entendimento do processo de trabalho dos catadores, buscou-se compreender quais os acúmenes que os mesmos tinham em relação aos direitos e deveres de um trabalhador e desses sobre o trabalho com coleta de resíduos. Sobre os direitos:

Empregado: se fosse em outro lugar a gente teria direito a INPS, né? Mas aqui tem direito a nada. Já já eu digo: “- vou colocar ele (empregador) na justiça”... ele vai ter que vender a carroça, é só o que ele tem (ela ri da situação). (Joaquina);

[...] Então o que eu vejo no direito é a gente que trabalha deveria de ter um salário mais...melhor, não é? você sabe quantas toneladas de lixo a gente tira da rua por ano? Que a prefeitura não gastou um centavo? (Josué de Castro);

Percebe-se, nitidamente, que os entrevistados sabem a importância que representam no cenário em que os cercam, além da contribuição valiosa de seus trabalhos em prol da sociedade. Chegam até a esclarecer o quanto contribuem como serviço público, pois, a mesma atividade de coleta é de obrigatoriedade do poder execu- tivo Municipal, ou seja, da Prefeitura, mas que, em troca, são desprestigiados pela sociedade oportunista.

Além do ideal de fuga do trabalho por meio da aposentadoria, um desencantamento da cidadania desses catadores que se colocam sem direitos, desconhecem deveres e algumas vezes refletem todo o preconceito da sociedade em relação a este tipo de trabalho à proporção que se colocam no mesmo patamar simbólico da matéria a qual trabalham: "o lixo". Quando se questionou sobre os deveres: "Eu não entendo disso não..." (Nelson Rodrigues); “Um dos deveres que eu acho que o homem que trabalha na reciclagem é deve sujar a rua” (Josué de Castro).

Aqueles que labutam na catação do lixo se traduzem pela exclusão de direitos trabalhistas e previdenciários, o que corrobora a afirmação destas pessoas em uma atividade estigmatizada, os quais não possuem condições mínimas de vida assim como não são reconhecidos como semelhantes, não têm direito a ter direito, e permanecem ali por não terem uma oportunidade laboral que condiga com a realidade social e econômica (CAVALCANTE; FRANCO, 2007; SOUSA, 2007)

\subsection{LIVRE EXPRESSÃO}

No final da entrevista provocou-se o catador para que o mesmo avaliasse seu trabalho e que falasse, abertamente, um pouco mais sobre sua rotina diária; observou-se uma insatisfação com a atividade, o reconhecimento de um trabalho de risco e da sobrecarregada carga de trabalho, apesar do orgulho em saber que desta humilde função eles tiram o sustento e a sobrevivência diante das desigualdades sequeladas pelo modo de produção vigente:

Aa gente trabalha que nem burro... (Josué de Castro). Aqui querendo ou não a gente tá arriscando a vida da gente. Porque a gente pode pegar uma infecção, se cortar, essas coisas assim... mas se tivesse outro meio de serviço é claro que ninguém ia querer tá catando papel”. (Joaquina).

0 projeto do governo é: reciclar mais, reciclar mais, e proteger o meio ambiente... quando aparece uma cooperativa que diz que quer ajudar a gente... é pra ele (responsável pela cooperativa) comprar o que a gente 
arruma... esse tipo de cooperativa eu não quero, eu prefiro ficar assim mesmo... (Josué de Castro).

Medidas ativas e intervencionistas que busquem a promoção e proteção de direitos sociais, considerando o trabalho como a edificação da cidadania, por meio de órgãos competentes, são necessárias para a garantia de um patamar mínimo de vida para todos, cabendo ao Estado o dever desta garantia principalmente àqueles que não têm acesso a esses direitos (AITH, 2006)

\section{CONSIDERAÇÕES FINAIS}

Mesmo com o reconhecimento da CBO do catador de recicláveis, os profissionais da Beira da Maré reconhecem, mesmo indiretamente, que não gozam de nenhum amparo referente aos direitos sociais: não trabalham de carteira assinada, não recebem salário mínimo, seguro desemprego, férias, décimo-terceiro, não são capacitados, nem uniformizados, e não fazem uso de equipamentos de proteção individual. Ou seja, trata-se de um cidadão marginalizado pela sociedade, haja vista não ser albergado diretamente pela Constituição Federal Brasileira, embora exerça uma tarefa de considerável importância social.

As esfinges nas articulações no processo de trabalho e na comercialização dos recicláveis neste grupo explanam uma relação frágil e a necessidade de implantação de políticas com fins de reconhecimento social assim como intervenções que fortaleçam a formação de uma rede de cooperação e de condições laborais seguras. Por meio, por exemplo, de um reordenamento destes profissionais como realizado com os ambulantes da praia de Boa Viagem, em Recife-PE, ou como os taxistas que tiveram garantidos os benefícios previstos no Regime Geral de Previdência Social (RGPS) e na Consolidação das Leis do Trabalho (CLT).

A semântica do lixo, o refúgio pela falta de oportunidades e a exploração que contribui com a miséria humana, aliados ao não reconhecimento dos catadores de resíduos como trabalhadores e detentores de direitos, os colocam em um ambiente à margem das políticas sociais.
Embora escrito em 1948, a poesia de Manuel Bandeira mostra-se atual ao retratar o cenário do homem-urubu: "Vi ontem um bicho; na imundície do pátio; catando comida entre os detritos.; ...0 bicho não era um cão, não era um gato, não era um rato. 0 bicho, meu Deus, era um homem."

\section{REFERÊNCIAS}

\section{AITH, Fernando Mussa Abujamra. Teoria geral do}

direito sanitário brasileiro. 2006. Tese (Doutorado em Saúde Pública) - Faculdade de Saúde Pública, Universidade de São Paulo, São Paulo, SP, 2006.

\section{ALVES FILHO, Manuel. As heroínas de Tejucupapo.}

Jornal da Unicamp. Campinas, São Paulo. Ano XXV, 2011. Disponível em: <http://www.unicamp. br/unicamp/unicamp_hoje/ju/agosto2011/ju501_ pag12.php>. Acesso em: 29 jan. 2016.

\section{ANDRADE, Michely Peres de. Nós é que}

corrompemos o filme, nós! carnavalização, sexualidade e o impacto da obra de Nelson Rodrigues no cinema brasileiro. 2007. 109 folhas. Mestrado (Dissertação) - Sociologia, Universidade Federal de Pernambuco, 2007.

BARDIN, L. Análise de conteúdo. Lisboa: Edições 70, 1979. 229p.

BRASIL. Consolidação das leis do trabalho. Decretolei no 5.452, de $1^{\circ}$ de maio de 1943. Aprova a consolidação das leis do trabalho. 104.ed. São Paulo: Atlas, 2000. Coletânea de Legislação.

\section{BRASIL. Constituição (1988). Constituição da}

República Federativa do Brasil. Brasília, DF: Senado

Federal: Centro Gráfico, 1988. 292p.

BRASIL. Ministério Nacional da Saúde. Conselho

Nacional de Saúde. Resolução 466/12 sobre

pesquisa envolvendo seres humanos. Bioética 2012. 
CARMO, Scarlet. A semântica do lixo e o desenvolvimento socioeconômico dos catadores de recicláveis: considerações sobre um estudo de caso múltiplo em cooperativas na cidade do Rio de Janeiro. Cad. EBAPE.BR, Rio de Janeiro, v.7, n.4, dez. 2009 .

CASTRO, Josué de. Geografia da fome: o dilema brasileiro: pão ou aço. Rio de Janeiro: Antares, 1984.

CAVALCANTE, Sylvia; FRANCO, Márcio Flavio Amorim. Profissão perigo: percepção de risco à saúde entre os catadores do Lixão do Jangurussu. Rev. MalEstar Subj., Fortaleza, v.7, n.1, mar. 2007.

CAPELLE, M.C.; MELO, M.C.O.L.; GONÇALVES, C.A. Análise de conteúdo e análise de discurso nas ciências sociais. Rev Admin UFLA, v.5, n.1, p.69-85 janeiro 2003;

DALL'AGNOL, C.M.; FERNANDES, F.S. Saúde e autocuidado entre catadores de lixo: Vivências no trabalho em uma cooperativa de lixo reciclável [número especial]. Rev. Latino-am Enfermagem, v.15, p.729-735, 2007.

FIOCRUZ. Urubu preto. 2013. Disponível em: <http://www.fiocruz.br/biosseguranca/Bis/infantil/ urubupreto.htm>. Acesso em: 3 mar. 2013.

INSTITUTO DE PESQUISA ECONÔMICA APLICADA (IPEA). Boas práticas de gestão de resíduos sólidos urbanos e de logística reversa com a inclusão de catadoras e de catadores de materiais recicláveis. Rio de Janeiro, 2015. Disponível em: <http:// www.ipea.gov.br/agencia/images/stories/PDFs/ relatoriopesquisa/2015.11.18-relatorio_boas\%20 praticas.pdf>. Acesso em: 25 jul. 2016

KELSEN, Hans. Teoria pura do direito. 4.ed. São Paulo: Martins Fontes, 427p. 2009.

KOIFMAN, Sérgio. Geração e transmissão da energia elétrica: impacto sobre os povos indígenas no Brasil.
Cad. Saúde Pública, Rio de Janeiro, v.17, n.2, p.413423, mar-abr., 2001.

MENDES, Eugênio Vilaça. As redes de atenção à saúde. Brasília: Organização Pan-Americana da Saúde, 2.ed., 2011. Disponível em: <http://apsredes. org/site2012/wp-content/uploads/2012/03/Redesde-Atencao-mendes2.pdf>. Acesso em: 14 nov. 2012.

\section{MINISTÉRIO DO TRABALHO E EMPREGO.}

\section{Classificação Brasileira de Ocupações: $\mathrm{CBO}$}

2002. Brasília: MTE, 2002. Disponível em: <http:// www.mtecbo.gov.br/cbosite/pages/legislacao.jsf>. Acesso em: 1 fev. 2012.

MIURA, P.C.O. Tornar-se catador: uma análise psicossocial. 2004. Dissertação (Mestrado em Psicologia Social) -Pontifícia Universidade Católica de São Paulo. São Paulo, SP, 2004.

NETTO, José Paulo. Crise do capital e consequências societárias. Serv. Soc. Soc., São Paulo, n. 111, p. 413-429, jul./set. 2012.

PADILHA JÚNIOR, Josesito Moura do Amaral. Especialização em filosofia moderna do direito. 2007. Disseratção (Mestrado) - Universidade Estadual do Ceará, Fortaleza, CE, 2007.

SIQUEIRA, Mônica Maria; MORAES, Maria Silvia de. Saúde coletiva, resíduos sólidos urbanos e os catadores de lixo. Ciênc. saúde coletiva, Rio de Janeiro, v.14, n.6, dez. 2009.

SOUSA, Cleide Maria de. A dinâmica prazersofrimento na ocupação de catadores de material reciclável estudo com duas cooperativas no DF. 2007. Dissertação. (Mestrado em Psicologia) Universidade de Brasília, Brasília, DF, 2007.

VELLOSO, M.P. Os catadores de lixo e o processo de emancipação social. Ciênc. Saúde Coletiva, v.10, p.49-56, 2005. 
1 Enfermeira; Professora Assistente, Universidade Federal de Pernambuco, Centro Acadêmico de Vitória - UFPE/CAV; Mestre em Saúde Coletiva. E-mail: maripernambucana@yahoo.com.br

2 Cirurgiã Dentista, Prefeitura da cidade do Recife; Especialista em Saúde da Família. E-mail: odontonai@yahoo.com.br

3 Bacharel em Geografia; Professor do Instituto Federal de Educação, Ciência e Tecnologia de Pernambuco - IFPE; Doutor em geografia. E-mail: anselmo_cesar@yahoo.com.br

4 Estudante de Enfermagem pela UFPE/CAV. E-mailk: deboramenf98@ gmail.com

5 Advogado; Bacharel em Direito e Licenciado em Letras. E-mail: sandroupe@hotmail.com 